\title{
Evaluation of variability of silymarin complex in Silybi mariani fructus harvested during two production years
}

Abstract Milk thistle [Silybum marianum (L.) Gaertn.], a member of Asteraceae family, is one of the most cultivated medicinal plants widespread throughout the world. The pharmacological drug is a ripe fruit without pappus - Silybi mariani fructus - containing flavonolignans and generating silymarin complex. In folk medicine, it is used for the treatment of liver disorders, kidney problems, rheumatism as well as gastronomic disturbances, cardiac and neurotic disorders, and fever. The components of silymarin complex are useful in cancer prevention and treatment. The aim of the study was to determine the amount of silymarin complex contained in the fruit of the harvest of two consecutive years and how much they differ from one another. Representative samples of fruit were collected in 2015 and 2016 and distributed by a company Agrofos (Slovakia). Regarding the analytical method, we used a high-performance liquid chromatography (HPLC); the method was approved by the European Pharmacopoeia 10. The statistical significance was on the level $P<0.05$. The total content of silymarin complex was $15.28 \pm 0.06 \mathrm{~g}^{\mathrm{kg}} \mathrm{g}^{-1}$ (in 2015) and $16.65 \pm 0.09$ g. $\mathrm{kg}^{-1}$ (in 2016). In both studied years, the highest representation of silybin B was observed $\left(7.04 \pm 0.07 \mathrm{~g} . \mathrm{kg}^{-1}\right.$ versus $5.92 \pm 0.08$ $\left.\mathrm{g} . \mathrm{kg}^{-1}\right)$. The differences between the individual fractions of the silymarin complex were statistically significant. There was also a significant difference of $9 \%$ in the total silymarin content between 2015 and 2016 . In conclusion, we can state that both samples of Silybi mariani fructus meet the requirements of the European Pharmacopoeia.

Keywords Silybum marianum - silymarin complex - HPLC

\section{INTRODUCTION}

Milk thistle [Silybum marianum (L.) Gaertn.] belongs to the Asteraceae family. This plant, originated in the Mediterranean region, is widespread throughout the world and has been grown throughout Europe, Africa, China, India and Australia for centuries (Polyak et al., 2013). Ražná et al. (2015) stated that it is one of the most cultivated medicinal plants on the Slovak market. It was cultivated on more than 1000 hectares in 2014 and 2015. The pharmacological drug forms ripe fruit without pappus, known as Silybi mariani fructus (Nagy et al., 2015). The fruits are achenes, dark brown to black colour, mostly flattened and oval. The length of the fruit ranges from 5 to $7 \mathrm{~mm}$, width from 2 to $3 \mathrm{~mm}$ and thickness is about $1.5 \mathrm{~mm}$ (Abenavoli et al., 2010). During the harvest, the entire flower heads are cut, even with inflorescence, just before the fruit ripens. Obtained fruits are rich in flavonoids, which are concentrated

*E-mail:haban@fpharm.uniba.sk,miroslav.haban@uniag.sk ORCID: 0000-0002-8013-0088. in the pericarp and seed (Andrzejewska et al., 2011; Giuliani et al., 2018). These biologically active phytochemicals, flavonolignans (silybin $A$ and silybin $B$, isosilybin $A$ and isosilybin $B$, silydianin, silychristin, isosilychristin and others) and flavonoid taxifolin are collectively known as silymarin (Pendry et al., 2017). The silymarin complex forms 60\%-80\% of the extract of Silybi mariani fructus. The silymarin content most often ranges from $1 \%$ to $3 \%$ of dry matter, but can exceed $8 \%$ (Karkanis et al., 2011; Lucini et al., 2015). When isolated from fruit, a multi-stage purification takes place, including extraction with ethyl acetate. This is an achieved enrichment of pharmacologically active flavonoids, while neutral or undesirable components are removed (Jedlinszki et al., 2016). Silymarin and its flavonolignans are commercially available in various formulations containing fruit extracts such as liquid

O Open Access. $\odot 2021$ European Pharmaceutical Journal, published by Sciendo. (cc) BY-NC-ND This work is licensed under the Creative Commons Attribution-NonCommercialNoDerivatives 3.0 License. 
extracts, capsules and tablets as well as in combination with synthetic chemical drugs or other herbal materials (Elateeq et al., 2020). Silybi mariani fructus are used as a medicine for hemorrhoids and heart disorders (Ghorbani, 2005), while roots and stems are used as a medicine for blood pressure and fever (Mirdeilami et al., 2011). The plant has a long history as a medicinal plant in folk medicine used for the treatment of liver disorders, kidney problems, rheumatism, gastronomic disturbances, cardiac disorders and fever (Marmouzi et al., 2021). Qin et al. (2017) found out that the silymarin also shows antioxidant and anti-diabetic activities. It was shown to be a putative neuroprotective agent against many neurological diseases including Alzheimer's and Parkinson's diseases and cerebral ischaemia (Borah et al., 2013). In addition, silymarin possesses antioxidant, anti-inflammatory and anti-fibrotic properties. It stimulates the biosynthesis of proteins, increases lactation and possesses immune-modulation activity (Abenavoli et al., 2010). Silymarin also shows in vitro efficacy as a cancer chemopreventive agent by arresting human prostate carcinoma proliferation in cancer cell cultures (Tyagi et al., 2002) and in human cancer models (Singh et al., 2002). Silybin, one of the constituents of silymarin, was included in the list of molecules useful in a broad-spectrum integrative approach for cancer prevention and treatment (Block et al., 2015). The anticancer efficacy of silybin is exerted through its ability to affect cancer cell proliferation and metabolism, inflammation and angiogenesis (Deep \& Agarwal, 2010). Silibinin clearly demonstrates the inhibition of multiple cancer cell signalling pathways, including a growth inhibition, inhibition of angiogenesis, chemosensitization and the inhibition of invasion and metastasis. The cumulative evidence implicates that silibinin is a potential agent for a cancer chemoprevention and chemotherapy (Li et al., 2010). Several studies have reported a beneficial effect of silymarin in different experimental models of acute and chronic inflammation, for example, in rats with formalin-induced paw oedema (Alhadidi et al., 2009). The findings by Li et al. (2016) demonstrate that silymarin is able to attenuate the airway inflammation induced by a cigarette smoke extract in human bronchial epithelial cells. Ripe seeds contain a large amount of oil (approximately 200-300 g. $\mathrm{kg}^{-1}$ ). Although it contains a relatively high amount of fatty acids (linoleic, linolenic, oleic and arachidic acid), it is a by-product of the industrial production of silymarin and must be removed from seeds before the extraction. Relatively large amounts of strongly lipophilic organic solvents, most often hexane or petroleum ether, are used for degreasing. The oil from milk thistle is used in foods and pharmaceutical industries, but due to ineffective reasons of exploitation and lack of cost-effective technologies, it is relatively rare on the market (Abouzid et al., 2016; Mei et al., 2013). The total yield of milk thistle and silymarin varies depending on environmental conditions, genotypes, sowing and harvest dates as well as gaps between rows and different farming practices (Karkanis et al., 2011).

\section{METHODS}

For this experiment, we used representative samples of fruit collected in 2015 and 2016 and distributed by the company Agrofos (Slovakia). The samples were analysed according to the guidelines of the European Pharmacopoeia (Ph. Eur. 10), which were partially modified by the methodological procedure. High-performance liquid chromatography method (HPLC) was applied to evaluate the silymarin complex of Silybi mariani fructus, using Agilent 1200 Infinity system. The research was carried out at the Department of Sustainable Agriculture and Herbology of Slovak University of Agriculture in Nitra.

The samples were ground in a grinder and $5 \mathrm{~g}$ was placed in the apparatus for continual extraction. We added $100 \mathrm{ml}$ of petroleum ether and let it heat in a water bath for 8 hours. We added $100 \mathrm{ml}$ of methanol to the sample and placed it in the apparatus where it was extracted in a water bath for another 5 hours. After the evaporation of the methanol extract, the sample was concentrated to a volume of about 30 $\mathrm{ml}$. The extraction flask and filter were washed with methanol, and the extract was filled in up to $50 \mathrm{ml}$. Consequently, we prepared the reference solution by dissolving the dried thistle extract and by diluting the sample to $100 \mathrm{ml}$ with the same solvent.

The following were the HPLC conditions: column with length I $=0.125 \mathrm{~m}$ and with diameter $=4 \mathrm{~mm}$; stationary phase $-5 \mu \mathrm{m}$ silica gel end-capping octadecylsilyl; mobile phase-a mixture of phosphoric acid, methanol and water (0.5:35:65), and a mixture of phosphoric acid, methanol and water (0.5:50:50) with the flow $0.8 \mathrm{ml} \cdot \mathrm{min}^{-1}$. The detection was carried out by spectrophotometer at $288 \mathrm{~nm}$ and injection volume $10 \mu \mathrm{l}$.

Concerning the identification of silymarin complex fractions, we used the record from the chromatogram of the dried milk thistle's extract and from the chromatogram of the reference solution to correctly identify the area and height of the peaks for silychristin, silydianin, silybin A, silybin B and isosilybin A $+B$ (Fig. 1). The peak areas of the respective diastereomers were calculated by the percentage of the total peak area of a known concentration of the isomeric flavonolignan mixture. To obtain the results, we calculated the specific weights of flavonolignans presenting the proportional relations between the individual peak areas and their corresponding applied quantity.

The statistical evaluation of data was carried out by using the program STATISTICA CZ version 10 and ANOVA main effects by means of Fisher's LSD test at the statistical significance level $\mathrm{a}=0.05$.

\section{RESULTS}

Concerning the experimental part of presented study, two parallel analyses and measurements were performed in four repetitions. There were 6 major flavonolignans (silychristin, 
silydianin, silybin $A$, silybin $B$, isosilybin $A$ and isosilybin $B$ ) in the silymarin complex of the analysed samples. Individual components of the silymarin complex were identified by the size of the peaks detected by HPLC analysis (Fig. 2) and converted to $\mathrm{g}_{\mathrm{kg}}{ }^{-1}$. The results are reported as mean \pm standard deviation (SD) and median. In each observed year, the differences between the representations of individual components of the silymarin complex were statistically significant $(P<0.05)$. In a sample of Silybi mariani fructus collected in 2015 (Table 1), the value of silybin B was twice as high as the value of silybin $A$. The common value of isosilybin

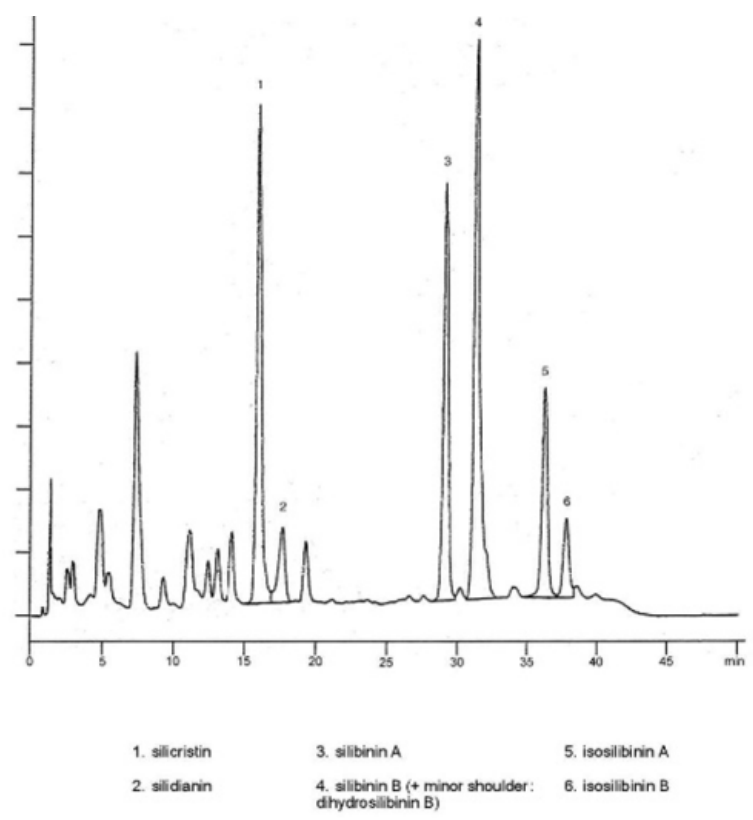

Figure 1. Chromatogram of Silybi mariani fructus according to the European Pharmacopoeia 10.
$A$ and isosilybin B was the second most abundant silymarin fraction. This was followed by silydianin with the smallest average value in the set of silymarin components; the lowest measured value of this component being $0.88 \mathrm{~g}^{\mathrm{kg}} \mathrm{kg}^{-1}$ and the highest $0.96 \mathrm{~g}^{\mathrm{kg}} \mathrm{kg}^{-1}$. Analogous results were achieved in 2016 (Table 2), when the highest proportion of silybin B component was achieved. Compared to the previous year, it was lower by $1.12 \mathrm{~g} . \mathrm{kg}^{-1}$. The amount of silychristin in 2016 ranged from $4.40 \mathrm{~g} \cdot \mathrm{kg}^{-1}$ to $3.79 \mathrm{~g} . \mathrm{kg}^{-1}$. The average value of silybin A was lower by 0.10 g. $\mathrm{kg}^{-1}$ compared to 2015 , while the common value of isosilybin A + B fractions increased by $0.89 \mathrm{~g}^{\mathrm{kg}}{ }^{-1}$. This year was also recorded the lowest value of the silydianin component. Its amount ranged from $1.56 \mathrm{~g}^{\mathrm{kg}}{ }^{-1}$ to 1.94 g. $\mathrm{kg}^{-1}$. Between 2015 and 2016, the period monitored in terms of qualitative production of Silybi mariani fructus for the determination of silymarin, there was a significant difference $(P<0.05)$ in observed values. The results showed that after counting all silymarin components, the silymarin complex was 1.37 g. kg ${ }^{-1}$ higher in 2016 than in 2015. This represents a difference of $9 \%$. After evaluating the ratio of individual fractions, we can state that we did not work with samples of fruit of different chemotypes.

\section{DISCUSION}

In a scientific study carried out by Wianovska and Wiśniewski (2015), a pressurized liquid extraction to prepare samples was used. This isolated the silymarin mixture in a one-step extraction process and, therefore, reduced the extraction time and volumes of solvents used. Using this method, the total content of the silymarin complex was $22.7 \mathrm{~g} . \mathrm{kg}^{-1}$ (2.27\%). Compared to values in presented study, there was a difference of $0.74 \%$ concerning fruit collected in 2015 and the difference of $0.6 \%$ regarding the fruit collected

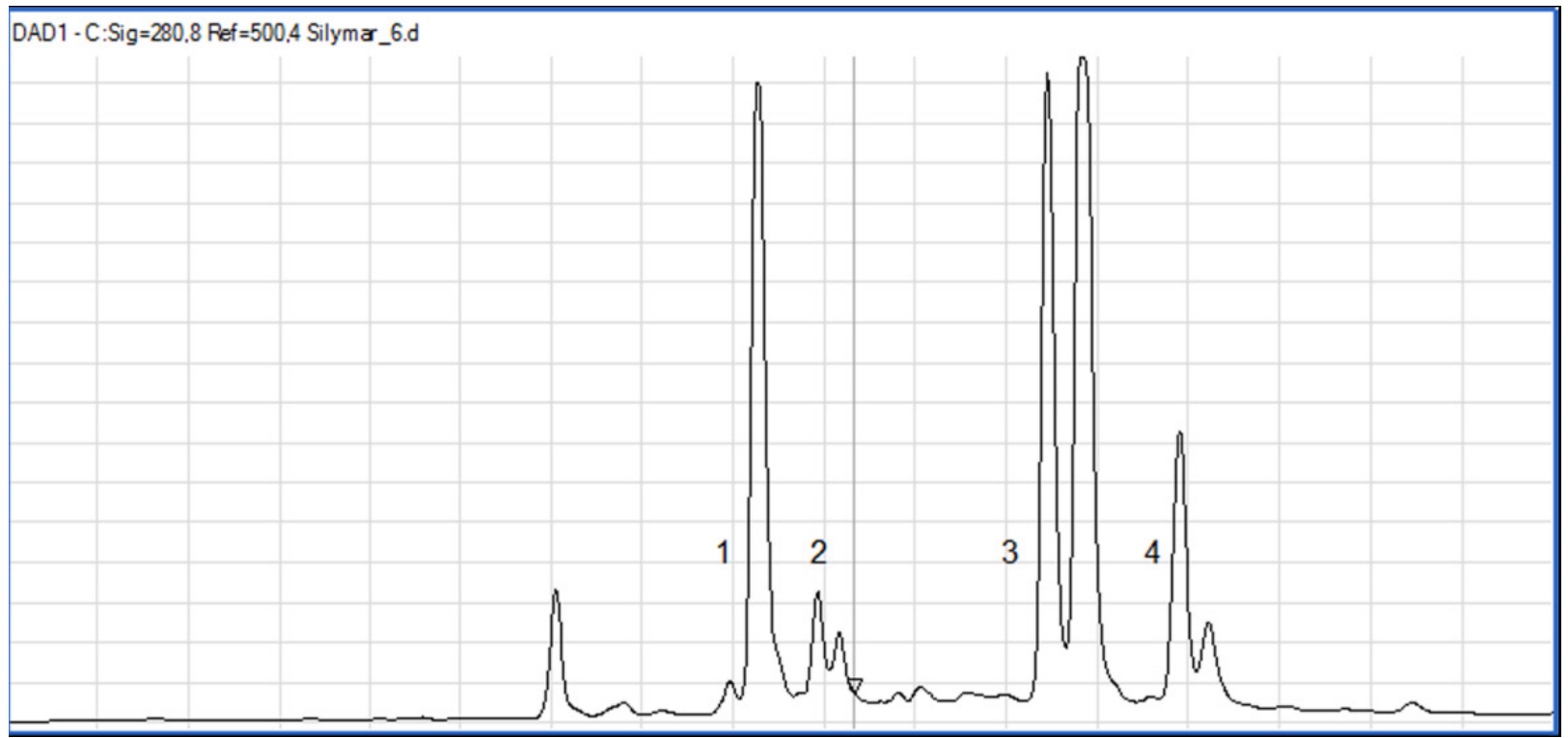

Figre 2. Chromatogram of Silybi mariani fructus (2015). 1 - silychristin, 2 - silydianin, 3 - silybin A, B, 4 - isosilybin A, B. 
Table 1. Fractions of silymarin complex $\left(\mathrm{g} \cdot \mathrm{kg}^{-1}\right)$ in Silybi mariani fructus, $2015(n=4)$.

\begin{tabular}{|c|c|c|}
\hline $\begin{array}{c}\text { Silymarin } \\
\text { components }\end{array}$ & Mean \pm SD & Median \\
\hline Silychristin & $3.18 \pm 0.06^{\mathrm{a}}$ & 3.18 \\
\hline Silydianin & $0.91 \pm 0.01^{\mathrm{b}}$ & 0.90 \\
\hline Silybin A & $3.06 \pm 0.06^{\mathrm{c}}$ & 3.07 \\
\hline Silybin B & $7.04 \pm 0.07^{\mathrm{d}}$ & 7.07 \\
\hline Isosilybin A + B & $1.09 \pm 0.05^{\mathrm{e}}$ & 1.10 \\
\hline Summary & $15.28 \pm 0.06^{\mathrm{A}}$ & 15.27 \\
\hline
\end{tabular}

Different indices after the numerical values indicate significant differences at the level of $P<0.05$. The indices $a, b, c, d, e$ represent a statistically significant difference between the individual components of the silymarin complex and ${ }^{A}$ indicates a significant difference in content of silymarin compared to the content in 2016.

Table 2. Fractions of silymarin complex $\left(\mathrm{g}^{\mathrm{kg}} \mathrm{g}^{-1}\right)$ in Silybi mariani fructus, $2016(n=4)$.

\begin{tabular}{|c|c|c|}
\hline $\begin{array}{c}\text { Silymarin } \\
\text { components }\end{array}$ & Mean \pm SD & Median \\
\hline Silychristin & $4.03 \pm 0.24^{\mathrm{a}}$ & 3.97 \\
\hline Silydianin & $1.76 \pm 0.14^{\mathrm{b}}$ & 1.78 \\
\hline Silybin A & $2.96 \pm 0.15^{\mathrm{a}}$ & 2.99 \\
\hline Silybin B & $5.92 \pm 0.08^{\mathrm{c}}$ & 5.92 \\
\hline Isosilybin A + B & $1.98 \pm 0.05^{\mathrm{d}}$ & 2.00 \\
\hline Summary & $16.65 \pm 0.09^{\mathrm{B}}$ & 16.66 \\
\hline
\end{tabular}

Different indices after the numerical values indicate significant differences at the level of $P<0.05$. The indices ${ }^{a, b, c, d}$ represent a statistically significant difference between the individual components of the silymarin complex, and ${ }^{B}$ indicates a significant difference in content of silymarin compared to the content in 2015.

in 2016. However, the whole process of analysis is timeconsuming. Nevertheless, calibration models are currently being developed for highly efficient and fast determination methods to substitute the HPLC method (Ashie et al., 2021). A promising alternative is a near-infrared (NIR) spectroscopy, a fast and non-destructive method for the analysis of samples without the need of sample pretreatment (Vagnerova et al., 2016). This NIR technique gives information about structural and physical qualities of materials based on the radiation transmittance or reflectance at wavelengths in various ranges (Rodriguez-Saona et al., 2000). The proposed method offers a promising approach to the determination of the quality and quantity of active ingredients for its rapid and nonpolluting properties and low costs (Ashie et al., 2021). Using NIR technique, Vagnerova et al. (2016) found out that the varieties of milk thistle (Silyb and Mirel) have different ratio of the main silymarin complex components. They also proved that the calibration model of studied varieties can be used to identify an unknown sample. This model is able to classify these varieties. Drouet et al. (2019) used ultrasound extraction to determine the content of the silymarin complex, which was at least $1.80 \mathrm{~g}^{\mathrm{kg}} \mathrm{kg}^{-1}$, and a liquid extraction to quantify the flavonolignans. They observed that silybin B presented the highest representation (7.52-1.29 $\left.\mathrm{g}^{\mathrm{kg}}{ }^{-1}\right)$, followed by silydianin (4.21-0.40 g. kg $\left.{ }^{-1}\right)$, isosilybin A (2.49-0.45 g.kg-1), silychristin (1.52-0.01 g. $\mathrm{kg}^{-1}$ ) and silybin A (1.09-0.01 g.kg-1). In another study, Ghafor et al. (2014) analysed the amount of flavonolignans and determined that the highest content within the silymarin complex was reached by silybin A. In all our measurements, we recorded the predominance of silybin B. Wallace et al. (2005) compared the yield of silymarin in the extraction with ethanol boiling at $78.3^{\circ} \mathrm{C}$ and ethanol heated to $60^{\circ} \mathrm{C}$. They found out that the average value of silymarin in the fruit in the extraction with boiling ethanol was 5.0 mg. ${ }^{-1}=5.0 \mathrm{~g}^{\mathrm{kg}}{ }^{-1}$, while a $60^{\circ} \mathrm{C}$ ethanol caused an increase in yield by 1.7 times. From this study, we can conclude that the preparation of mash or decoction of Silybi mariani fructus can degrade the whole silymarin complex and, at the same time, reduce the effects of the ingredients. The most studied substance from silymarin complex is silybin, which exists in the form of two stereoisomeric compounds: silybin A and silybin B. Poppe and Petersen (2016) presented in their study that the content of these components represents $10 \%-20 \%$ of the silymarin content, while isosilybin B represents only about $5 \%$ of its content. According to another study, using the same assay procedure as we used in our study, the silybin A content ranged from $0.44 \mathrm{~g} . \mathrm{kg}^{-1}$ to $11.77 \mathrm{~g} . \mathrm{kg}^{-1}$, while the silychristin content varied from $2.05 \mathrm{~g} . \mathrm{kg}^{-1}$ to $15.11 \mathrm{~g} \cdot \mathrm{kg}^{-1}$. The average content of isosilybin A was $4.70 \mathrm{~g}^{\mathrm{kg}} \mathrm{kg}^{-1}$ and 3.67 g. $\mathrm{kg}^{-1}$ (Arampatzis et al., 2018). Khan et al. (2015) reported that the concentrations of various silymarin components strongly depend on growth conditions, and stress conditions have a strong impact on its biosynthesis. According to the European Pharmacopoeia, which sets the minimum content of silymarin in the dried drug to $1.5 \%$, we can state that both samples meet the requirements of Pharmacopoeia $1.5 \%$ in 2015 and $1.7 \%$ in 2016).

\section{ACKNOWLEDGEMENTS}

We would like to thank Ing. Lubomír Kobida for the consultation and chemical analysis. This study was elaborated thanks to the support of the Operational Programme of Integrated Infrastructure for the Project: Long-term Strategic Research of Prevention, Intervention and Mechanisms of Obesity and Its Comorbidities, IMTS: 313011V344, cofinanced by the European Regional Development Fund, and project VEGA 1/0749/21. 
[1] Abenavoli L, Capasso R, Milic N, Capasso F. Milk thistle in liver diseases: past, present, future. Phytotherapy Research 2010;24:1423-1432.

[2] Abouzid SF, Chen SN, Mcalpine JB, Friesen JB, Pauli GF. Silybum marianum pericarp yields enhanced silymarin products. J. Fitote. 2016;56:136-143.

[3] Alhadidi Q, Ahmed ZA, Numan IT, Hussain SAR. Dose-dependent anti-inflammatory effect of silymarin in experimental animal model of chronic inflammation. Afr. J. Pharm. Pharmacol. 2009;3:242-247.

[4] Andrzejewska J, Sadowska K, Mielcarek S. Effect of sowing date and rate on the yield and flavonolignan content of the fruits of milk thistle (Silybum marianum L. Gaertn.) grown on light soil in a moderate climate. J. Ind. Crop. 2011;33:462-468.

[5] Arampatzis AD, Karkanis CA, Tsiropoulos GN. Siymarin content and antioxidant activity of seeds of wild Silybum marianum populations growing in Greece. J AAB. 2018;174.

[6] Ashie A, Lei $H$, Han B, Xiong M, Yan $H$. Fast determination of free components in milk thistle extract with a hand-held NIR spectrometer and chemometrics tools. Infra Phys Tech. 2021;113:103629.

[7] Block Kl, Gyllenhaal C, Lowe L, et al. Designing a broad-spectrum integrative approach for cancer prevention and treatment. Semin Cancer Biol. 2015;35:276-304.

[8] Borah A, Paul R, Choudhury S, et al. Neuroprotective potential of silymarin against CNS disorders: Insight into the pathways and molecular mechanisms of action. CNS. 2013;19:847-853.

[9] Deep G, Agarwal R. Antimetastatic efficacy of silibinin: molecular mechanisms and therapeutic potential against cancer. Cancer Metastasis Rev. 2010;29:447-463.

[10] Drouet S, Leclerc AE, Garros L. A Green Ultrasound-Assisted Extraction Optimization of the Natural Antioxidant and AntiAging Flavonolignans from Milk Thistle Silybum marianum (L.) Gaertn. Fruits for Cosmetic Applications. Antioxidants. 2019;8:304.

[11] Elateeq AA, Sun Y, Nxumalo W, Gabr MMA. Biotechnological production of silymarin in Silybum marianum L.: A review. J. BCAB. 2020;29:101775.

[12] European Pharmacopoeia: 10th Edition. Strasbourg: EDQM Publications; 2020.

[13] Ghafor Y, Mohammad NN, Salh DM. Extraction and Determination of Chemical Ingredients from Stems of Silybum Marianum. CMR. 2014;6:26-32.

[14] Ghorbani A. Studies on pharmaceutical ethnobotany in the region of Turkmen Sahra, north of Iran: (Part 1): General results. J Ethpharm. 2005;102:58-68.

[15] Giuliani C, Tani C, Bini LM, Fico G, Colombo R, Martinelli T. Localization of phenolic compounds in the fruits of Silybum marianum characterized by different silymarin chemotype and altered colour. J. Fitote. 2018:210 -218.

[16] Jedlinszki N, Kálomista I, Galbács G, Csupor D. Silybum marianum (milk thistle) products in Wilson's disease: a treatment or a threat? J. Her. Med. 2016;6:157-159.
[17] Karkanis A, Bilalis D, Efthimiadou A. Cultivation of milk thistle (Silybum marianum L. Gaertn.), a medicinal weed. J Ind Crop. 2011;1:825-830.

[18] Khan AM, Abbasi HB, Shah AN, Yücesan B, Ali H. Analysis of metabolic variations throughout growth a nd development of adventitious roots in Silybum marianum L. (Milk thistle), a medicinal plant. PCTOC. 2015;123:501-510.

[19] Li D, Hu J, Wang T, et al. Silymarin attenuates cigarette smoke extract-induced inflammation via simultaneous inhibition of autophagy and ERK/p38 MAPK pathway in human bronchial epithelial cells. Sci rep. 2016;6.

[20] Li L, Zeng J, Gao Y, He D. Targeting silibinin in the antiproliferative pathway. Expert Opinion on Investigational Drugs. 2010;19:243255.

[21] Lucini L, Pellizzonii M, Pellegrino R, Molinari GP, Colla G. Phytochemical constituents and in vitro radical scavenging activity of different Aloe species. J Food Chem. 2015;170:501-507.

[22] Marmouzi I, Bouyahaya A, Ezzat MS, Jemli EM, Kharbach M. The food plant Silybum marianum (L.) Gaertn.: Phytochemistry, Ethnopharmacology and clinical evidence. J Ethpharm. 2021;265:113303.

[23] Mei L, Wang L, Li Q, Yu J, Xu X. Comparison of acid degumming and enzymatic degumming process for Silybum marianum seed oil. J. Sci. Food Agric. 2013;93:2822-2828.

[24] Mirdeilami ZS, Barani H, Mazandarani M, Heshmati AG. Ethnopharmacological Survey of Medicinal Plantsin Maraveh Tappeh Region, Northoflran. J.P.P. 2011;2:325-336.

[25] Nagy M, Mučaji P, Grančai D. Farmakognózia. Biologicky aktívne rastlinné metabolity a ich zdroje. Bratislava: Herba; 2015.

[26] Pendry BA, Kemp V, Hughes MJ, et al. Silymarin content in Silybum marianum extracts as a biomarker for the quality of commercial tinctures. J Herb Med. 2017;10:31-36.

[27] Polyak JS, Ferenci P, Pawlotsky MJ. Hepatoprotective and Antiviral Functions of Silymarin Components in HCV Infection. PMC. 2014;57:1262-1271.

[28] Poppe L, Peretsen M. Variation in the flavonolignan composition of fruits from different Silybum marianum chemotypes and suspension cultures derived thereform. J Phyto. 2016;131:68-75.

[29] Qin N, Jia C, Xu J, Li D et al. New amides from seeds of Silybum marianum with potential antioxidant and antidiabetic activities. J. Fitot. 2017;119:83-89.

[30] Ražná $K$, Hlavačková L, Bežo $M$ et al. Application of the RAPD and miRNA markers in the genotyping of Silybum marianum (L.) Gaertn. Acta fytotechn zootechn. 2015;18:83-89.

[31] Rodriguez-Saona EL, Fry SF, Calvey ME. Use of Fourier Transform Near-Infrared Reflectance Spectroscopy for Rapid Quantification of Castor Bean Meal in a Selection of Flour-Based Products. J. Agric. Food. Chem. 2000;48:5169-5177.

[32] Singh RP, Tyagi AK Zhao J, Agarwal R. Silymarin inhibits growth and causes regression of established skin tumors in SENCAR mice via modulation of mitogen-activated protein kinases and induction of apoptosis. Carcin. 2002;23:499-510.

[33] Tyagi A, Bhatia N, Condon MS, Bosland MC, Agarwal C, Agarwal R. 
Eur. Pharm. J. 2021, 68(1), 40-45

Evaluation of variability of silymarin complex in Silybi mariani fructus harvested during two ...

Antiproliferative and apoptotic effects of silibinin in rat prostate cancer cells. Pros. 2002;53:211-217.

[34] Vagnerova L, Bradacova M, Pluhackova H. The Determination of Contained Compounds in Milk Thistle (Silybum marianum L. (Gaertn.)). Mendel Net. 2016;23:168-172.

[35] Wallace SN, Carrier DJ, Clausen EC. Batch solvent extraction of flavanolignans from milk thistle (Silybum marianum L. Gaertner). Phytochem. Anal. 2005;16:7-16.

[36] Wianowska D, Wiśniewski M. Simplified Procedure of Silymarin Extraction from Silybum marianum L. Gaertner. J. Chrom. Sci. 2015;53:366-372. 